\title{
0 movimento da competência informacional: uma perspectiva para o letramento informacional
}

\author{
B ernadete C ampello \\ $M$ estre em biblioteconomia \\ Professora da Escola de Ciência da Informação da U FM G \\ E-mail: campello@eci.ufmg.br
}

\begin{abstract}
Resumo
O objetivo deste trabalho é analisar a competência informacional (information literacy), que surgiu nos Estados Unidos na década de 1970 e representa o esforço da classe bibliotecária americana para ampliar o seu papel dentro das instituições educacionais. O movimento ocorreu em circunstâncias peculiares ao contexto daquele país, acompanhando a evolução das ações educativas da classe bibliotecária. O discurso da competência informacional desenvolve-se ao redor de quatro aspectos: a sociedade da informação, as teorias educacionais construtivistas, a tecnologia da informação e o bibliotecário. Considerando-se que o termo começa a aparecer na literatura brasileira de biblioteconomia e ciência da informação, propõem-se $o$ estudo mais aprofundado do conceito e o estabelecimento de uma agenda de pesquisa para o Brasil, buscando sua inserção nas teorias sobre letramento, que se vêm desenvolvendo na área de educação.
\end{abstract}

\section{Palavras-chave}

Competência informacional; Habilidades informacionais; Educação de usuários; Biblioteca escolar; Letramento.

\section{The moviment of informational competency: a perspective for infoliteracy}

\begin{abstract}
This study aims to analyse the information literacy movement, which started in the United States in the seventies. That movement represents the effort the American library profession is doing in order to get more visibility in the educational community. Its appearance occurred in peculiar circumstances, along with changes in the librarian teaching role concerning bibliographic instruction. The discourse of the information literacy movement evolves around the following aspects: the information society, constructivist perspective of education, information technology and the librarian. Considering the word is coming into view in the Brazilian literature on library and information science this article suggests the establishment of a research program towards our reality in an attempt to integrate information literacy in the education field.
\end{abstract}

\section{Keywords}

Information literacy; User education; School library.

\section{IN TRO D U ÇÃ O}

Nos dias de hoje, as mudanças por que tem passado a biblioteconomia vêm ensejando o surgimento de novos termos que possam representar de forma mais clara as atividades que, na atualidade, são demandadas do profissional da informação. Competência informacional (information literacy) é um desses termos. U sado inicialmente nos Estados U nidos para designar habilidades ligadas ao uso da informação eletrônica, ele foi assimilado pela classe bibliotecária e atualmente inserese de forma vigorosa no discurso dos bibliotecários americanos, sendo alvo de interesse crescente por parte de bibliotecários de outros países (Bruce, 1998; Bundy, 2001), aparecendo como tema de inúmeras publicações institucionais e constituindo a base de políticas de ação pedagógica de vários sistemas de bibliotecas escolares.

N o Brasil, o termo está em fase de construção. Foi mencionado pela primeira vez por Caregnato $(2000, p$. 50), que o traduziu como "alfabetização informacional" em um texto em que propunha a expansão do conceito de educação de usuários e ressaltava a necessidade de que as bibliotecas universitárias se preparassem para oferecer novas possibilidades de desenvolver nos alunos habilidades informacionais necessárias para interagir no ambiente digital. A autora não se aprofundou na questão terminológica, acabando por preferir o termo habilidades informacionais. Hatschbach (2002), citado por Dudziak (2003), também enfoca a information literacy no contexto digital, utilizando o termo no original.

0 trabalho de Dudziak (2003) discutiu a information literacy além dos limites da tecnologia, considerando-a um conceito inclusivo, capaz de englobar as diversas gamas de literacy que surgiram na última década* e que, segundo a autora, constituem aspectos compartimentalizados da literacy. Propõe diversas possibilidades para a tradução do termo: "alfabetização informacional, letramento, literacia**, fluência informacional, competência em informação", mostrando preferência

* A autora apresenta os seguintes exemplos dessas literacies: "cultural, tecnológica, acadêmica, marginal".

** Literacia é 0 termo que em Portugal corresponde a letramento. 


\section{0 movimento da competência informacional: uma perspectiva para o letramento informacional}

pelo último, embora acabe por utilizar o termo no original, já que seu trabalho não tem a pretensão de propor uma tradução para o termo "nem resolver eventuais questões de gênero" (Dudziak, 2003, p. 24). A tradução do termo information literacy como competência informacional havia sido feita por Campello (2002) na perspectiva da biblioteca escolar, em texto que sinalizava para o potencial desse conceito como catalisador das mudanças do papel da biblioteca em face das exigências da educação no século XXI.

Percebe-se, assim, que os autores brasileiros que trataram da information literacy, embora trabalhando em perspectivas distintas, têm em comum o fato de perceberem a necessidade de ser este 0 momento de se ampliar a função pedagógica da biblioteca (ou, em outras palavras, construir um novo paradigma educacional para a biblioteca) e de se repensar o papel do bibliotecário. É o momento, segundo Dudziak (2003, p. 34), de buscar "o trabalho cooperativo para o desenvolvimento de novas abordagens relativas à filosofia e às práticas educacionais ligadas à information literacy".

N esse sentido, a contribuição que este artigo pretende dar refere-se especificamente à identificação das circunstâncias do surgimento do conceito de "competência informacional" no âmbito da biblioteca escolar. Consideramos que é preciso evitar a utilização irref letida de um termo que surgiu em circunstâncias históricas peculiares. Devemos ter em mente a necessidade de integrar, em nossas ações, os avanços teóricos e práticos já alcançados nos estudos sobre literacy no Brasil. Assim, no âmbito da educação básica, que constitui o foco de nossos estudos, parece que o conceito de letramento seria o mais adequado para embasar ações que busquem ampliar a ação educativa da biblioteca.

\section{A FUNÇÃO EDUCATIVA DA BIBLIOTECA ESC O LAR}

A função educativa da biblioteca torna-se visível com o aparecimento do "serviço de referência" (referenceservice) e se amplia com a introdução da "educação de usuários", conjunto de atividades que, ao contrário do serviço de referência, apresentam uma característica proativa, realizando-se por meio de ações planejadas de uso da biblioteca e de seus recursos.

A educação de usuários como antecedente da competência informacional

A té a década de 1950, a educação de usuários praticamente não existia nas bibliotecas escolares americanas. Estas funcionavam como local de estudo para os alunos, dedicando-se os bibliotecários a realizar apenas o serviço de referência. No início da década de 50 , surge o serviço chamado de bibliographic instruction, e, sem dúvida, o termo define com precisão seu objetivo inicial: instruir o leitor no uso da coleção, treinando-o para manusear fontes de informação consideradas apropriadas e relevantes para a aprendizagem de determinado tópico do currículo. Essa fase da educação de usuários caracterizou-se como "abordagem da fonte" (Kuhlthau, 1987, p. 23) ou "foco na coleção" (Stripling, 1996, p. 633).

Em 1960, as diretrizes para bibliotecas escolares da A merican Association of School Librarians-AASL* mantiveram o foco na coleção, embora recomendando que 0 ensino do uso dos materiais da biblioteca fosse feito não isoladamente, mas ligado às disciplinas do currículo. Era a chamada "abordagem guia" ((Kuhlthau, 1987, p. 24) ou "foco no programa" (Stripling, 1996, p.634).

A biblioteca era então influenciada pelas teorias educacionais que privilegiavam métodos de aprendizagem dinâmicos e centrados no aluno e que tomavam o lugar do ensino verbalista centrado no professor. Essas teorias estimularam a ação dos bibliotecários, que percebiam que a biblioteca tinha contribuição importante a dar no apoio às novas estratégias didáticas.

N essa época, já existiam no país alguns programas de educação de usuários que enfatizavam habilidades de questionamento e solução de problemas**. Esses novos modelos exigiam um bibliotecário que participasse ativamente do planejamento curricular e que estivesse disposto a abandonar a postura de isolamento, concentrada apenas nas atividades da biblioteca e, ao mesmo tempo, privilegiasse estratégias de aprendizagem condizentes com as teorias educacionais recentes (Stripling, 1996, p. 635). Tudo isso constituiu campo fértil que levou os bibliotecários a desenvolver a preocupação quase obsessiva em provar o valor de sua função educativa e o desejo de contribuir com os ideais pedagógicos da época (Baker, 1979, p. 456).

Em 1975, percebida a necessidade de se ampliar o espaço da biblioteca no processo pedagógico, novos padrões***

\footnotetext{
*AMERICAN ASSOCIATION OF SCHOOL LIBRARIANS. Standards for school library programs. Chicago: A LA, 1960.

** U m dos mais conhecidos foi o programa desenvolvido por Patrícia Knapp, bibliotecária do M onteith College, que usava uma abordagem de solução de problemas bastante arrojada para a época. KN APP, P. The M onteith College Library Experiment. N ew York: Scarecrow, 1966. *** AMERICAN ASSOCIATION OF SCHOOL LIBRARIANS/ ASSOCIATION FOR EDUCATIONAL COMMUNNICATIONS AND TECHNOLOGY. Media programs: district and school. Chicago: ALA, 1975.
} 


\section{Bernadete C ampello}

foram lançados, dessa vez recomendando a participação do bibliotecário no planejamento curricular. Havia, na época, entendimento de que as mudanças, especialmente aquelas relacionadas à tecnologia da informação, iriam influenciar fortemente 0 trabalho do bibliotecário. Tornavam-se freqüentes os questionamentos a respeito da função do bibliotecário e da biblioteca nesse ambiente mutante e com novas perspectivas para a educação. Percebia-se queas bibliotecas, na sua função de repositório de cultura ou local de desenvolvimento da apreciação da leitura literária, embora desempen hassem papéis importantes, não se mostraram capazes de aten der a todas as necessidades identificadas como cruciais para a sobrevivência e a realização em um mundo extremamente complexo, abundante em informação e que mudava rapidamente, conforme afirmava Liesener (1985, p.13).

N essa ocasião o termo information literacy foi usado pela primeira vez. Em 1974, Paul Zurkowsky, então presidente da Information Industries Association*, mencionou-o em relatório submetido à $\mathrm{N}$ ational $\mathrm{C}$ ommission on Libraries and Information Science, no qual sugeria que o governo norte-americano se preocupasse em garantir que a população do país desenvolvesse competência informacional que the permitisse utilizar a variedade de produtos informacionais disponíveis no mercado. M unidas dessas competências, as pessoas poderiam aplicá-las na solução de problemas no seu trabalho - dizia Behrens (1994, p. 310) -, e a indústria da informação teria mercado garantido, a longo prazo, para seus produtos.

Em 1976, o termo competência informacional apareceu em perspectiva diferente. Dois autores ( $\mathrm{H}$ amelink citado por Behrens, 1997, p. 310; O wens, 1976, p. 27) usaram o termo vinculando-o à questão da cidadania: segundo eles, cidadãos competentes no uso da informação teriam melhores condições de tomar decisões relativas à sua responsabilidade social. A competência informacional, embora ainda não claramente definida, era vista como solução para questões de extrema complexidade. Passariam ainda vários anos até que o termo fosse assimilado na sua perspectiva biblioteconômica.

\footnotetext{
* A Information Industries Association, fundada em 1968 nos Estados U nidos, congrega atualmente mais de 550 empresas comerciais, cujo objetivo é criar e distribuir produtos, serviços e sistemas de informação, principalmente em formatos digitais. "Indústria da informação" é a expressão usada para designar o conjunto dessas organizações que fornecem produtos e serviços de informação, utilizando novas tecnologias e agregando valor ao material, permitindo o manejo inovador das informações.
}

No campo da biblioteconomia, a década de 1980 viu 0 aparecimento de novas diretrizes (e não mais padrões) da AASL, denominadas Information Power: Guidelines for School Libraries M edia Programs*, queprocuraram definir com mais clareza a função pedagógica do bibliotecário, advogando a parceria entre professores, dirigentes escolares e bibliotecários no planejamento do programa da biblioteca, de acordo com as necessidades específicas da escola. U ma das funções do bibliotecário seria a de professor, encarregado de ensinar não apenas as habilidades que vinha tradicionalmente ensinando (localizar e recuperar informação), mas também envolvido no desenvolvimento de habilidades de pensar criticamente, ler, ouvir e ver, enfim ensinando a aprender a aprender. O utra função prevista para o bibliotecário era a de consultor didático, encarregado de integrar 0 programa da biblioteca ao currículo escolar, colaboran do no processo de ensino/ aprendizagem e assessorando no planejamento e na implantação de atividades curriculares.

N essa época, a teoria construtivista da aprendizagem já se fazia presente nos estudos biblioteconômicos e influenciou 0 aparecimento da estratégia didática denominada resource based learning, quesurgiu no C anadá e se popularizou nos Estados U nidos na década de 1980. A aprendizagem baseada em recursos, que enfatizava a utilização de uma variedade de fontes e de tecnologias de informação, teve influência marcante nos trabalhos sobre competência informacional e até hoje é citada por autores que tratam do assunto (Loertscher \& W ools, 1997, p. 337).

No Reino U nido, era publicado nessa ocasião o trabalho de M ichel Marland, Information Skills in the Secondary Curriculum. Foi esse o momento em que se iniciaram as tentativas de se identificar com clareza o elenco de habilidades informacionais que se pretendia que os alunos dominassem** (Loertscher \& Wools, 1997, p. 337). Esse trabalho também teve influência no movimento da competência informacional nos Estados U nidos.

*AMERICAN ASSOCIATION OF SCHOOL LIBRARIANS/ ASSOCIATION FOR EDUCATIONAL COMMUNICATIONS AND TECHNOLOGY. Information power: guidelines for school libraries media programs. Chicago: ALA, 1988.

** As competências de informação de $M$ arland são: "O que é que eu preciso fazer? (formulação e análise de necessidades); onde é que eu posso ir? (identificação e avaliação de recursos adequados); onde é que eu consigo a informação? (localização individual de recursos); que recursos devo usar? (exame, seleção e rejeição de recursos); como devo usar os recursos? (interrogação dos recursos); o que devo registrar? (registro e armazenamento de informação); será que tenho a informação de que preciso? (interpretação, análise, síntese, avaliação); como devo fazer a apresentação? (apresentação, comunicação); o que é que eu obtive? (avaliação)." (Alves, 1999, p. 77). 


\section{0 movimento da competência informacional: uma perspectiva para o letramento informacional}

A dificuldade que a classe bibliotecária americana tinha em demonstrar efetivamente sua capacidade de influenciar positivamente a educação veio à tona com a divulgação, em 1983, do documento $\mathrm{A} N$ ation at Risk: the Imperative for Educational Reform*, que apresentou um diagnóstico da situação de deterioração em que se encontrava o ensino público nos Estados U nidos. 0 documento, embora enfatizasse a aprendizagem de habilidades intelectuais superiores, não mencionou as bibliotecas, organizações que tinham "potencial para contribuir para a melhoria significativa demandada pelas escolas e por todas as instituições educacionais da sociedade", nas palavras de Liesener (1985, p. 11). Demonstrando seu desapontamento com a omissão, os bibliotecários reagiram energicamente, manifestando-se por meio de uma profusão de publicações, em que tentavam explicitar o papel que a biblioteca tinha a desempenhar no esforço de formar a comunidade de aprendizagem proposta em $\mathrm{A} N$ ation at Risk.

A reação mais enfática veio na forma de um documento chamado Libraries and the Learning Society: Papers in Response to A N ation at Risk, publicado em 1984 pela ALA, em que os autores demonstravam a contribuição que a biblioteca escolar poderia oferecer para uma educação que ensinasse 0 aluno a aprender a aprender $e$ desenvolvesse habilidades para buscar e usar informação, consideradas essenciais para viver em uma sociedade complexa e mutável.

N essa época, já se percebia que a primeira versão do Information Power estava superada. A lguns bibliotecários consideravam que as funções do bibliotecário, conforme definidas no documento, haviam sido pensadas em uma visão da educação tradicional, centrada no professor (no caso, no bibliotecário) e no ensino. As teorias educacionais exigiam que se redesenhassem novas formas de mediação para o bibliotecário, em um modelo em que o usuário ficaria no centro do processo de aprendizagem. Stripling (1996), conhecida especialista em biblioteca escolar, sugeriu os seguintes papéis para 0 bibliotecário, enfatizando sua função pedagógica:

- Caregiver: essa função relaciona-se com a idéia de que o processo de aprender envolve uma dimensão afetiva; é importante respeitar a individualidade e 0 interesse pessoal do aluno. Assim, a função do bibliotecário seria a de apoiar a aprendizagem individualizada, auxiliando cada aluno em suas necessidades específicas, respeitando seu estilo de aprendizagem;

\footnotetext{
* UNITED STATES. National Commission on Excellence in Education. A nation at risk: the imperative for educational reform. W ashington, DC: U.S. Government Printing Office,1983.
}

- Orientador (Coach): a idéia de que 0 aluno seja responsável pela construção de seu conhecimento coloca o bibliotecário na posição de estimular a aprendizagem, levando 0 aluno a buscar as fontes, estratégias e respostas para suas necessidades;

- Elo (C onnector): as duas funções anteriores seriam de responsabilidade conjunta do professor e do bibliotecário; este último, entretanto, assumiria uma função que normalmente não é assumida pelo primeiro: a de conectar os alunos com as idéias concretizadas no universo dos recursos informacionais disponíveis. $E$, à medida que esse universo se tornasse cada vez mais complexo, essa função prevaleceria sobre as outras;

- C atalisador (C atalyst): a função coloca o bibliotecário como catalisador das mudanças na escola, tendo em vista a sua posição na estrutura escolar. Como colaborador no planejamento curricular e facilitador da aprendizagem, o bibliotecário estaria em uma posição privilegiada, por ter uma visão global do processo de aprendizagem em todas as áreas (Stripling, 1996, p. 641-649).

As sugestões anteriores já apontavam as mudanças consideradas necessárias na primeira versão do Information Power. A nova versão, publicada em 1998 e rebatizada deI nformation Power: Building Partnerships for Learning (1998), inovou ao apresentar o bibliotecário como líder na implementação do conceito de competência informacional no ambiente escolar.

\section{A perspectiva da competência informacional}

0 novo Information Power apresentou um conjunto de recomendações para desenvolver competências informacionais desde a fase de educação infantil até 0 ensino médio. Nessa versão, as habilidades de informação foram claramente definidas, não só em termos teóricos, mas também na perspectiva de aplicação. Foram incluídas nove habilidades informacionais, divididas em três grupos que abrangem: 1) competência para lidar com informação; 2) informação para apren dizagem independente; 3) informação para responsabilidade social, conforme apresentado no quadro a seguir.

Especificando as habilidades informacionais de maneira detalhada, o Information Power pode ser considerado o documento que concretiza a assimilação do conceito de competência informacional pela classe bibliotecária. Começou, a partir daí, intenso movimento que tornou o conceito um tema de destaque não só nos Estados U nidos, mas também em diversos países, com a criação de entidades, a realização de encontros profissionais, a 
implantação de programas e o desenvolvimento de pesquisas que levaram a competência informacional a se constituir um dos assuntos mais discutidos atualmente na área de biblioteconomia.

\section{O DISCURSO DA COMPETÊNCIA INFORMACIONAL}

A competência informacional foi a bandeira erguida pela classe bibliotecária americana para tirar a biblioteca do estado de desprestígio em que se encontrava. 0 tom do discurso do movimento é claramente 0 de exortação e de urgência para as mudanças demandadas pela sociedade da informação. É uma estratégia retórica que se centra na persuasão e que procura levar os praticantes a se convencerem da necessidade de transformação inevitável que virá com as novas exigências da sociedade da informação (Reis, 1999, p. 146). Os bibliotecários são incitados a tomar atitude proativa, a fim de participar do esforço educativo que requer mais do que a visão ingênua e simplista do processo de busca e uso da informação. É necessária uma abordagem realista para o problema; apenas "Iouvações" sobre as vantagens e os benefícios da biblioteca seriam improdutivas, diz Liesener (1985, p. 12). Essa é também a tônica de uma palestra virtual proferida por Ross Todd (2001), na conferência anual da International Association of School Librarianship-ASL, instituição que abraçou com vigor a causa da competência informacional. N essa palestra, a classe é conclamada a pautar sua prática no princípio de que a biblioteca atue na perspectiva de "knowledge space, not information place; connections, not collections; actions, not position; evidence, not advocacy' (Todd, 2001).

É um discurso de dupla face: de um lado, realça a competência tradicional e única do bibliotecário na abordagem crítica da informação, na sua capacidade para lidar com uma variedade de formatos de informação e na sua sensibilidade para entender as necessidades de informação de diferentes categorias de usuários (AASL, 1998, p. 3); de outro, insiste que o bibliotecário deva mudar, adotando atitudes condizentes com o novo ambiente social. A simples disponibilização de materiais na biblioteca, combinada com o nível limitado de auxílio ao usuário, não é considerada suficiente para atender à crescente sofisticação das demandas de aprendizagem sugeridas para a escola na sociedade da informação. Também não são suficientes as concepções "abstratas e ambíguas" que até então embasaram o desenvolvimento dos serviços bibliotecários, afirma Liesener (1985, p. 13). 0 foco da biblioteca tem de se deslocar dos recursos para o aluno, a fim de criar a comunidade de aprendizagem (AASL, 1998, p. v).

\section{QUADRO 1 \\ 0 poder da informação: construindo parcerias para aprendizagem}

\section{Nove normas para a competência informacional}

\section{Competência informacional}

1. 0 aluno que tem competência informacional acessa a informação de forma eficiente e efetiva.

2. O aluno que tem competência informacional avalia a informação de forma crítica e competente.

3. 0 aluno que tem competência informacional usa a informação com precisão e com criatividade.

\section{A prendizagem independen te}

4. O aluno que tem capacidade de aprender com independência possui competência informacional e busca informação relacionada com os seus interesses pessoais com persistência.

5. 0 aluno que tem capacidade de aprender com independência possui competência informacional e aprecia literatura e outras formas criativas de expressão da informação.

6. 0 aluno que tem capacidade de aprender com independência possui competência informacional e se esforça para obter excelência na busca de informação e de geração de conhecimento.

\section{Responsabilidade social}

7. $O$ aluno que contribui positivamente para a comunidade de aprendizagem e para a sociedade tem competência informacional e reconhece a importância da informação para a sociedade democrática.

8. 0 aluno que contribui positivamente para a comunidade de aprendizagem e para a sociedade tem competência informacional e pratica o comportamento ético em relação à informação e à tecnologia da informação.

9. 0 aluno que contribui positivamente para a comunidade de aprendizagem e para a sociedade informacional tem competência informacional e participa efetivamente de grupos, a fim de buscar e gerar informação.

AMERICAN ASSOCIATION OF SCHOOL LIBRARIANS/ ASSOCIATION FOR EDUCATIONAL COMMUNICATIONS AND TECHNOLOGY. Information power: building partneships for learning. Chicago: ALA, 1998. p. 8-9 (tradução nossa).

0 tom de urgência, de exortação à mudança e de desafio que perpassa 0 discurso está presente no documento A Position Statement on EffectiveSchool Library Programs in Canadá, da Canadian Library A ssociation-C LA, quando afirma que o programa da biblioteca é crucial na educação de crianças e jovens (CLA, 2000). Educar é agora um desafio, diz Kuhlthau, uma das pesquisadoras mais destacadas na área de biblioteca escolar e especialmente no movimento de competência informacional. Ela afirma: "O desafio para a escola da sociedade da informação é educar as crianças para viver e aprender em ambiente rico em informação. 
Os professores não podem fazer isso sozinhos. 0 bibliotecário desempenha papel fundamental no enfrentamento desse desafio" (Kuhlthau, 1999, p. 7-8, tradução nossa).

\section{O AMBIENTE DA COMPETÊNCIA IN FO RMACION AL}

\section{A sociedade da informação}

A "sociedade da informação" é o espaço mais abrangente por onde trafega 0 movimento da competência informacional. É o mundo "alterado pela rápida disponibilização de uma abundância de informação, em uma variedade de formatos" (AASL, 1998). Essa frase sintetiza o discurso dos bibliotecários sobre o contexto que irá justificar a exigência inevitável da competência informacional. É um ambiente tão diferente e mutante que exige novas habilidades para nele se sobreviver. Espaço problemático e interconectado, que vai demandar que as crianças desenvolvam capacidades que Ihes permitam aprender a reconhecer e lidar com visões de mundo diferentes das suas, habilidades essenciais para sobrevivência, segundo um dos position paper da AASL, Elementary School Library M edia Centers as Essential Components in the Schooling Process (Vandergrift \& H annigan, 1986, p. 172). De fato, "a explosão da informação ... al terou dramaticamente o conhecimento e as habilidades de que [0 aluno] precisará para viver produtivamente no século XXI“ (AASL, 1998, p. 2). As mudanças são constantemente lembradas, e 0 bibliotecário é incitado a aceitar e enfrentar desafios complexos, conforme propõe Ross Todd. "Em um período de profundas mudanças na educação e intenso aumento da acessibilidade da informação, ambos de certa forma impelidos pela tecnologia de redes, o desafio para os bibliotecários, de projetar um futuro superior para os ambientes informacionais da escola é, ao mesmo tempo, complexo e potencialmente desafiador" (Todd, 2001, tradução nossa).

Além disso, a sociedade da informação é ambiente de oportunidades e promessas. A qui, percebese uma retórica utópica que oferece esperança e, mais que isso, fornece um roteiro, instruções precisas, para resolver problemas e atingir a transformação necessária (D ay, 1998, p.646). "A competência informacional prepara o indivíduo para tirar vantagem das oportunidades inerentes à sociedade da informação globalizada", afirma o documento Information Literacy: a Position Paper on Information Problem Solving (AASL, 2001). Constitui espaço que abriga possibilidades para se discutirem questões como a capacidade de o país de competir internacionalmente, bem como as injustiças sociais e econômicas, desde que as pessoas sejam preparadas para lidar com a enorme quantidade de informação disponível, isto é, sejam competentes em informação (ALA, 1989). A sociedade da informação traz grandes promessas para a aprendizagem no contexto das bibliotecas digitais, embora encontrar significados em ambientes de abun dância informacional não seja fácil, como reconhece Kuhlthau (1997, p. 722).

\section{A tecnologia da informação}

Se a sociedade da informação é ambiente de abundância informacional, a tecnologia é o instrumento que vai permitir lidar com o problema, potencializando o acesso à informação e conectando as pessoas aos produtos da mente, segundo afirma o documento $2020 \mathrm{~V}$ ision, que traça as bases da política de informação do Reino U nido (U nited Kingdom, 1999). Ela é aliada do bibliotecário na "intensificação do acesso à e uso da informação". N a ideologia da mudança, a tecnologia constitui 0 instrumento de transformação da sociedade, ou até da própria humanidade. 0 discurso transformador assume que a mudança que virá liberará o potencial humano e resolverá conflitos de todos os tipos, esquecendo-se de que tecnologias desenvolvidas anteriormente falharam nesse intento (D ay, 1998, p.642).

Há também a preocupação constante em mostrar que a fluência em tecnologia é apenas um dos componentes da competência informacional. No documento da Association of College and Research Libraries (ACRL), que define os padrões de competência informacional para o ensino superior, essa fluência é considerada como "estrutura intelectual para compreender, encontrar, avaliar e usar informação - atividades que podem ser realizadas em parte através da fluência em tecnologia, em parte através de métodos de pesquisa sólidos, mas principalmente através de discernimento e raciocínio" (ACRL, 2000). O s bibliotecários são então aconselhados a resistir à sedução da tecnologia, mas, ao mesmo tempo, a compreender seu impacto e a planejar estruturas em que a tecnologia embase a aprendizagem significativa e não a substitua (O berman, 1996, p. 323). A insistência em mostrar a tecnologia como mero instrumento da competência informacional não impede 0 aparecimento de inúmeros textos que destacam seu papel no processo de aprendizagem (Bruce \& Leander, 1997; Kuhlthau, 1997; Goldfarb, 1999; Gordon, 1999, e muitos outros), sinalizando para a preocupação com a questão que não está resolvida. 


\section{Bernadete C ampello}

\section{As teorias educacionais}

A consistência das teorias pedagógicas no discurso da competência informacional vai ocorrendo à medida que o movimento amadurece. É preciso observar que, desde a década de 1950, já havia percepção, por parte dos bibliotecários, de que a biblioteca poderia embasar uma aprendizagem mais ativa, constituindo espaço para desenvolvimento de estratégias de apren dizagem condizentes com as teorias educacionais centradas no aluno. Os documentos institucionais sobre competência informacional mencionam à exaustão as habilidades que consideram essenciais para se sobreviver na sociedade da informação: habilidade de solucionar problemas, de aprender independentemente, de aprender ao longo de toda a vida, de aprender a aprender, de questionamento, de pensamento lógico, colocando-as na categoria de habilidades cognitivas de ordem superior ou de pensamento crítico. Insistem, então, em chamar a atenção para o potencial da biblioteca para 0 desenvolvimento dessas habilidades, mostran do que isso não irá ocorrer usando-se estratégias didáticas centradas no professor e no livro-texto. $M$ as as teorias que embasam estratégias adequadas de aprendizagem não eram exploradas em profundidade.

N os documentos mais recentes já se nota a tendência em tratar as teorias educacionais com maior cuidado. Os autores exploram a literatura educacional e aprofundam os conceitos, para então colocá-los na perspectiva da biblioteconomia (O berman, 1991; M acAdam, 1995; M cG regor, 1999).

\section{0 bibliotecário}

O bibliotecário é a figura central no discurso da competência informacional. Os autores fazem coro na exortação à transformação pela qual ele precisa passar, se quiser envolver-se no movimento. Longas listas de atribuições são elaboradas para descrever 0 que 0 novo bibliotecário, envolvido com a aprendizagem, deve ser e fazer. O s textos relembram a competência tradicional do bibliotecário no uso da informação e da tecnologia e na identificação de necessidades informacionais dos usuários e reafirmam a convicção no seu papel - único e vital - no desenvolvimento da competência informacional, desde que assuma as mudanças e se tran sforme em membro ativo da comunidade escolar, deixando para trás suas características de passividade e isolamento.

0 tema da parceria e da colaboração é recorrente no discurso. No Information Power, a parceria aparece na expressão que designa uma das funções do bibliotecário (instructional partner) que, na versão anterior do documento
(1988), aparecia como instructional consultant. R eforça-se, assim, a idéia de que professores e bibliotecários devem trabalhar em colaboração, como iguais (Liesener, 1985, p. 15). 0 desenvolvimento das habilidades informa-cionais é atividade conjunta de professores e bibliotecários que trabal ham em parceria para planejar, implementar e avaliar a aprendizagem (CLA, 2000; A ASL, 2001; ACRL, 2000).

A verdade é que essas funções propostas para 0 bibliotecário no novo ambiente informacional nos Estados U nidos vêm evoluindo ao longo do tempo, desde a publicação das primeiras diretrizes para bibliotecas escolares da A merican Library Association-A LA em 1945. A novidade refere-se à função de liderança que é posta para o bibliotecário e que, de certa forma, contraria todas as expectativas, levando-se em conta as características negativas que há longo tempo são imputadas a esse profissional (passividade, isolamento, inflexibilidade etc.), aliadas ao problema de identidade que afeta em especial o bibliotecário escolar (Liesener, 1985, p. 18).

A função de liderança foi inicialmente proposta por Stripling em 1996, quando sugeriu que o bibliotecário assumisse a função de "catalisador" das mudanças na escola. N o Information Power (AASL, 1998, p. 52) a função de liderança destaca-se como um dos três pilares do processo, e o bibliotecário é exortado a liderar a mudança (a partir da mudança na biblioteca) da própria escola como um todo. É mais uma responsabilidade para 0 bibliotecário, mas o entusiasmo, a vibração e 0 dinamismo do discurso embaçam as limitações e os problemas (resistência dos administradores, orçamentos limitados, desinteresse dos professores). Embaçam também o fato de que os bibliotecários se percebem como profissionais que ainda lutam dentro da própria escola com a falta de compreensão de sua função, falta de valorização de seu trabalho, falta de apoio para suas atividades; ao mesmo tempo, estão conscientes de sua imagem negativa e de seu baixo status (Todd, 2001). Tudo isso é posto de lado, pois, ao obter a visão clara dos objetivos de servir à comunidade de aprendizagem, o bibliotecário vai "desfrutar a recompensa sem precedentes" que virá do seu engajamento com a apren dizagem ativa e criativa e voltada para a solução de problemas (AASL, 1998, p. 47).

A qui o tom exortativo atinge seu ápice e revela com mais nitidez o descolamento da realidade. Realidade que se desnuda, quando se sabe que o "desafio" (no sentido de obstáculo) maior para o profissional que gerencia a biblioteca refere-se à tecnologia. Não a tecnologia como "oportunidade sem limites para a aprendizagem", mas aquela que sufoca o bibliotecário no seu dia-a-dia, trazendo problemas com equipamentos que precisam 


\section{0 movimento da competência informacional: uma perspectiva para o letramento informacional}

estar sempre atualizados e em constante manutenção, equipamentos que drenam os recursos financeiros da biblioteca, que sugam o tempo do bibliotecário, que precisa dominar as novidades, gerenciar o processo, ensinar alunos e professores a utilizar, tudo isso sem apoio especializado, sem pessoal e sem jornada extra de trabalho (Todd, 2001). A tecnologia, nessa situação, é algo pesado que demanda do bibliotecário não competência pedagógica, mas competência gerencial e técnica, que lhe permita atender aos intermináveis pedidos de ajuda para usar os equipamentos e controlar sua utilização (Chelton, 1999, p. 280). Assim, não é de se estranhar que o "desafio" da aprendizagem fique situado em um horizonte distante do bibliotecário, que, en redado nessa teia tecnológica, não consegue escapar da jornada de trabalho pesada, na qual "a situação vai-se complicando e, em certos dias, o caos a que se chega é positivamente assustador" (Todd, 2001).

Então, a tecnologia, em vez de constituir promessa de "apren dizagem rica e criativa", parece estar transforman do - papel educativo do bibliotecário em trabalho nãoqualificado e em função técnica de apoio (C helton, 1999, p. 280). N essa perspectiva, o discurso da competência informacional revela-se como retórica, e as dificuldades para se obter o tão desejado prestígio para a classe mostram-se em toda sua extensão.

\section{AS CRÍTICAS AO MOVIMENTO DA COMPETÊNCIA INFORMACIONAL}

A energia e a fartura das manifestações em prol da competência informacional contrastam com as escassas críticas de seus opositores que tentaram mostrar à classe as fragilidades do empreendimento. A penas cinco desses autores foram identificados.

As críticas atacam o estardalhaço, o tom de campanha publicitária do movimento (M CC rank, 1991, p. 38)*. Em artigo publicado no Library Journal, uma das revistas profissionais de biblioteconomia de maior tiragem nos Estados U nidos, M cCrank (1991) critica o tom de exortação dos documentos institucionais do movimento, questionando se ele efetivamente não consistiria em uma campanha para captar recursos para as bibliotecas. É seguido por Foster (1993, p. 344, 346), que ironiza ao dizer que "a literatura de biblioteconomia atualmente reverbera com o zelo missionário da causa da competência informacional", considerando-a basicamente como exercício de relações públicas.

\footnotetext{
* 0 autor se refere à campanha promovida no início da década de 1990 pela Association of College and Research Libraries (ACRL), divisão de bibliotecas universitárias da ALA
}

Crítica mais fundamentada ocorreu quando Lori Arp, bibliotecária da U niversity of Colorado, (instituição que esposou com vigor a causa da competência informacional*), publicou um pequeno artigo na seção Library Literacy da revista RQ da ALA. As ponderações da autora dizem respeito à palavra literacy, que forma a expressão utilizada na língua inglesa (information literacy). A autora identifica certa imprudência no uso da palavra literacy e chama atenção para a conotação política do termo, sua dependência do contexto em que ocorre e a tendência cada vez maior de sua avaliação e medição em larga escala.

"Se preten demos abraçar o movimento da information literacy, devemos reconhecer esses aspectos e apoiar 0 desenvolvimento de amplas pesquisas sobre conceitos e habilidades de busca de informação em diferentes disciplinas. A té lá, devemos ser cuidadosos, ao utilizar o termo dentro da estrutura política em que vivemos, e não ter muita pretensão sobre nossa capacidade de produzir o que não podemos medir ou provar" (Arp, 1990, p. 49, tradução nossa).

A crítica de Arp foi a mais consistente em relação à questão da apropriação do termo literacy, tocada por outros autores apenas superficialmente (Foster, 1993, p. 346; O Isen \& Coons, citados por Behrens, 1994, p. 313). Anteriormente, Kuhlthau (1989, citada por Behrens, 1994) já havia mencionado a relação da information literacy com a leitura. Ela perguntava:

"O que significa dominar a leitura na sociedade da informação? A competência informacional está intimamente ligada à capacidade de leitura. Envolve a habilidade de ler e usar informação necessária para a vida cotidiana. Envolve também o reconhecimento da necessidade de informação e sua busca para tomar decisões bem embasadas. A competência informacional requer habilidades de lidar com massas complexas de informação geradas por computador e pela mídia, e aprender ao longo da vida, à medida que mudan ças sociais e técnicas demandem novas habilidades e conhecimentos (Kuhlthau, 1989, citada por Behrens, 1994, p. 313, tradução nossa).

Entretanto, a autora não avançou para estabelecer com mais precisão o relacionamento da competência informacional com o domínio da leitura.

\footnotetext{
* O utra bibliotecária da instituição, à época ocupando o cargo de diretora da biblioteca, Patrícia Senn Breivik, foi autora (juntamente com E. Gordon Gee, presidente da referida universidade) do livro Information Literacy: Revolution in the Library, publicado em 1989, que é extensamente citado na literatura sobre letramento informacional. Breivik é uma das mais destacadas defensoras do movimento.
} 


\section{Bernadete C ampello}

A percepção da fragilidade do conceito é unânime entre os autores que criticam a information literacy. M cC rank (1991, p. 38) denunciava o termo como vago e insípido, ao passo que Foster (1993, p. 344) considerava-o um "termo em busca de um significado". Snavely \& Cooper (1997) retomam e reforçam as críticas à fragilidade do termo ao divulgar opiniões de professores universitários sobre o mesmo*.

O s comentários desses professores ref letem a visão de pessoas de fora da área de biblioteconomia: oco, vazio, escorregadio, moeda passageira, coqueluche, sem sentido. M esmo assim, as autoras analisaram os argumentos a favor e contra o termo e concluíram que ele deve continuar a ser usado, desde que os bibliotecários privilegiem o "melhor significado do termo". Essa conclusão baseia-se na opinião das autoras de que literacy possua vários significados e um deles se aplica de forma adequada à expressão information literacy. É aquele que 0 considera enquanto "conhecimento básico de um campo ou assunto, diferente do conhecimento do especialista". As autoras argumentam que esse significado é cada vez mais difundido e tem sido utilizado para se referir às várias modalidades de literacy hoje possíveis** (Snavely \& Cooper, 1997, p. 12). A característica atual de mensuração que o termo denota pode então ser ignorada.

\section{CONSIDERAÇÕES FINAIS}

Podese dizer, portanto, que a expressão information literacy nos países avançados é do domínio dos bibliotecários. Embora empregado inicialmente em perspectiva gerencial ou de negócios, o termo capturou a imaginação daqueles profissionais, principalmente dos norteamericanos, que 0 tem usado como bandeira para levar avante 0 desejo de aumentar o prestígio da classe, o que seria conseguido com a ampliação da função pedagógica da biblioteca. Desde sua origem, essa função parece ter acompanhado a evolução da profissão. Ao se limitar ao atendimento a questões de referência e ao ensino de fontes de informação, o bibliotecário perdeu espaço no processo pedagógico. Agora, no ímpeto do movimento da competência informacional, pretende ocupar o espaço que considera seu. Tem a seu favor o fato de contar com bagagem de pesquisa acadêmica mais consistente e com evidências mais concretas sobre 0 impacto da biblioteca

\footnotetext{
* Essas opiniões foram coletadas pelas autoras em reuniões com professores de duas universidades (Lycoming College e Bucknell U niversity), para a preparação de um workshop a ser realizado durante a Pennsylvania Library Association Conference, em outubro de 1995. (Snavely e Cooper, 1997, p. 9 e 10).

${ }^{* *}$ As autoras listam diversas modalidades de literacy usadas com esse significado: computer literacy, cultural literacy, media literacy, television literacy, visual literacy, etc.
}

nos resultados escolares. A questão da tecnologia permanece uma faca de dois gumes: embora no discurso da competência informacional ela seja promessa de dias melhores para a profissão, pode, com as contradições que a caracterizam, inviabilizar as pretensões da classe. Entretanto, apesar de calcado em pretensa parceria com os educadores, o conceito continua limitado à literatura de biblioteconomia e ciência da informação. As críticas não foram suficientes para esfriar o entusiasmo do movimento, que se amplia e cativa bibliotecários de outros países (Bundy, 2001) que parecem nele encontrar soluções para seus problemas.

No Brasil, já se percebem claramente manifestações dos bibliotecários sobre a necessidade de ampliar a ação pedagógica da biblioteca. Se para isso formos utilizar 0 conceito de competência informacional, no que diz respeito à biblioteca escolar, devemos essencialmente levar em conta o panorama dos estudos sobre letramento, que é o conceito utilizado no âmbito do ensino básico para designar "o estado ou condição que assume aquele que aprende a ler ou escrever", entendendo-se então que "quem aprende a ler e a escrever e passa a usar a leitura e a escrita, a envolver-se em práticas de leitura e de escrita, torna-se uma pessoa diferente, adquire um outro estado, uma outra condição" (Soares, 2001, p. 17, 36). A ssim, a escrita traz conseqüências sociais, culturais, políticas, econômicas, cognitivas, lingüísticas, quer para o grupo social em que seja introduzida, quer para o indivíduo que aprenda a usá-la (Soares, 2001, p. 17).

O bserva-se que, na literatura sobre letramen to no B rasil, já há percepção de que existem vários tipos de letramento. Antônio Augusto Gomes Batista, um dos pesquisadores do C eale/ U FM G, que tem como foco de suas pesquisas questões ligadas ao letramento, identifica algumas dimensões desse fenômeno que, segundo ele, estão em fase de constituição. U ma delas diz respeito ao que ele chama de "novos tipos de letramento", isto é, relativo aos "novos tipos de textos, impressos, linguagens e suportes e seus impactos e repercussões" (Batista, 2000, p. 185). A ssim, percebe-se que há espaço para trabalhar a competência informacional no bojo das questões do letramento, 0 que nos levaria ao letramento informacional. A questão está em aberto; entretanto, é necessário mais do que uma discussão terminológica. 0 estabelecimento de uma agenda de pesquisa que contemple precisamente os problemas do nosso contexto social e a busca de aportes teóricos da área de educação (especificamente de letramento) poderão abrir caminhos para a desejada ampliação do papel educativo da biblioteca, sem isolar o bibliotecário no espaço da biblioteca. 


\section{0 movimento da competência informacional: uma perspectiva para o letramento informacional}

\section{A GRADECIMENTO}

\section{A gradeço à professora I sis Paim pelos comentários e sugestões ao texto.}

\section{REFERÊN CIAS}

ALVES, M arta Paula. Biblioteca escolar: tecnologias de informação e currículo. Liberpolis, n. 2, p. 69-80, 1999.

AMERICAN ASSOCIATION OF SCHOOL LIBRARIANS/ ASSOCIATION FOR EDU CATIONAL COMMUNICATIONS AND TECHNO LOGY. Information power: building partnerships for learning. Chicago, 1998.

Information literacy: a position paper on information problem solving. C hicago, 2001. Disponível em: <www.ala.org/aasl/positions/ ps_infolit.html >. Acesso em: 02 maio 2003.

Final report. Chicago, 1989. Disponível em <http:// www.ala.org/ Content/ $\mathrm{N}$ avigation M en U/ A C RL/ Publications/ White_Papers_and_Reports/Presidential_Committee_on Informātion Literacy. $\bar{h}$ tm>. A cesso em: 02 maio 2003.

ARP, L. Information literacy or bibliographic instruction: semantics or philosophy? RQ, v. 30, n. 1, p. 46-49, 1990.

ASSOCIATION OF COLLEGE AND RESEARCH LIBRARIES Information literacy competen cy for higher education. C hicago : ALA, 2000 Disponível em <http:// www.ala.org/ acrl/ ilcomstan.html > A cesso em: 03/01/2002.

BATISTA, A. A. G. Letramentos escolares, letramentos no Brasil. Educação em Revista, n. 31, p. 171-190, 2000.

BAKER. D. P. The media center: a review article. Library $Q$ uarterly, $v$. 49 , n. 4, p. 453-458, 1979

BEHRENS, S. J. A conceptual analysis and historical overview of information literacy. College \& Research Libraries, v. 55, n. 4, p. 309 322, 1994.

BRU CE, C. B.; LEANDER, K. M. Searching for digital libraries in education: why computers cannot tell the true. Library Trends, v. 45, $\mathrm{n}$. 4, p. 746-770, 1997

BRU CE, C. The experience of information literacy: toward a holistic model Disponível em: < http:// www.schools.nsw.edu.au/ schoollibraries/ scan/ 17 1998/171res.htm>. A cesso em: 02 maio 2003.

BUNDY, A. For a clever country: information literacy diffusion in the $21^{\text {st }}$ century. [S.I.] : A ustralian Library and Information Association 2001. Disponível em: < http:// www.library.unisa.edu.au/papers/ clever.htm> Acesso em: $27 \mathrm{dez} .2001$.

CAM PELLO , B. A competência informacional na educação para o século XXI. In: BIBLIOTECA escolar: temas para uma prática pedagógica. Belo Horizonte: Autêntica, 2002. p. 9-11.

CAN ADIAN LIBR ARY ASSOCIATION. A position statement on effective school library programs in Canadá. [S. I.], 2000. Disponível em: বhttp:// www.cla.ca/divisions/csla/ pub 3.htm>. A cesso em: 13 dez. 2001.

CAREGNATO， S. E. 0 desenvolvimento de habilidade informacionais: o papel das bibliotecas universitárias no contexto da informação digital em rede. Rev. de Bibliotecon. \& Comum., Porto Alegre v. 8, p. $47-55,2000$.

CHELTON, M. K. Structural and theoretical constraints on reference service in a high school library media center. Reference \& U ser Service Q uarterly, v. 38, n. 3, p. 275-282, 1999.

DAY, M. T. Transformational discourse: ideologies of organizational change in the academic library and information science literature. Library Trends, v. 46, n. 4, p. 635-667, 1998.

DUDZIAK, E. A. Information literacy: princípios, filosofia e prática. Ciência da Informação, Brasília, v. 32, n.1, p. 23-35, 2003.
FOSTER, S. Information literacy: some misgivings. American Libraries, v. 24, n. 4, p. $344-346,1993$.

GOLDFARB, E. K. Learning in a technological context. In: STRIPLIN G , B. K. Learning and libraries in an information age: principles and practice. Englewood : Libraries U nlimited, 1999. p. 83-129.

GORDON, M. W. M aking sense of a changing world: digitized primary source documents in schools. In: STRIPLIN G, B. K. Learning and libraries in an information age: principles and practice. Englewood: Libraries U nlimited, 1999. p. 196-205.

HATSCHBACH, M. H. L. Information literacy: aspectos conceituais e iniciativas em ambiente digital para o estudante de nível superior. 2002. Dissertação (M estrado em Ciência da Informação) -. IBICT, UFRJ, Rio de Janeiro. Rio de Janeiro, 2002.

KUHLTHAU, C. C. An emerging theory of library instruction. School Library M edia Q uarterly, v. 16, n. 1, p. 13-18, 1987.

Learning in digital libraries: an information search process approach. Library Trends, v. 45, n. 4, p. 708-724, 1997.

Literacy and learning for the information age. In STRIPLIN G , B. K. Learning and libraries in an information age. Englewood : Libraries Unlimited, 1999. p. 3-21.

LIESENER, J. W. Learning at risk: school library media programs in an information world. School Library M edia Q uarterly, v. 14, n. 1, p. 1120, 1985.

LOERTSCHER, D. V.; WOOLS, B. The information literacy movement of the school library media field: a preliminary summary of the research. In: LIGHTHALL, L.; HAYCOCK, K. Information rich but knowledge poor? Seatle : IASL, 1997. p. 337-358.

MACADAM, B. Sustaining the culture of the book: the role of enrichment reading and critical thinking in the undergraduate curriculum. Library Trends, v. 44, n. 2, p. 237-263, 1995.

MCCRANK, L. J. Information literacy: a bogus bandwagon? Library Journal, v. 116, n. 8, p. 38-42, M ay 11991.

M CGREGOR, J. H. How do we learn? In: STRIPLING, B. K. Learning and libraries in an information age: principles and practice. Englewood Libraries U nlimited, 1999. p. 25-53.

OBERM AN, C. A voiding the cereal syndrome or critical thinking in the electronic environment. Library Trends, v. 39, n. 3, p. 189-202, 1991.

OWENS, M. R. State government and libraries. Library Journal, v. 101, n. 1, p. 19-26, Jan.1 1976.

SM ALL, G. School libraries do make a difference. School Librarian, v. 46, n. 4, p. 174-175, 1998.

REIS, A. S. Retórica-ideologia-informação: questões pertinentes ao cientista da informação. Perspectivas em Ciência da Informação, v. 4, n. 2 p. 145-160, 1999.

SN AVELY, L.; COOPER, N. The information literacy debate. Journal of A cademic Librarianship, v. 23, n. 1, p. 9-13, Jan. 1997.

STRIPLING, B. K. Q uality in school library media programs: focus on learning. Library Trends, v. 44, n. 3, p. 631-656, 1996

TODD, R. Transitions for preferred futures of school libraries. In: THE 2001 IALS CONFERENCE, 2001, Auckland. Keynote paper. Seattle : International Association of School Librarianship, 2001. Disponível em : <http:// www.ials-slo.org/ virtualpaper2001.html >. A cesso em: 24 ago.2001

U NITED KINGDOM. Library and Information Commission. 2020 vision. 1999. Disponível em: < http:// www.lic.gov.uk.publications/ policyreports/2020.html. A cesso em: 03 jan. 2002.

VANDERGRIFT, K. E., HANNIGAN, J. A. Elementary school library media centers as essential components in the schooling process. School Library M edia Q uarterly, v. 14, n. 4, p. 171-173, 1986. 